\title{
Editorial V.14 N.33
}

\section{Marcela Guimarães e Silva}

PhD, Universidade Federal do Pampa / marcelaunipampa@gmail.com Orcid: 0000-0002-9752-2571 / lattes

\section{Tiago Costa Martins}

PhD, Universidade Federal do Pampa / tiagomartins@unipampa.edu.br Orcid: 0000-0003-0927-7148 / lattes 


\section{Fashion and creative economy}

The sectors of the creative industry can be analyzed by establishing an interrelationship between the dimensions of cultural/creative value and economic value. When imagining the configuration of concentric circles, as suggested by David Throsby (2008), we have that in the central circle are the sectors with greater cultural emphasis and in the outer circles are the sectors with greater economic emphasis. As other circles are inserted at the end of the center, the economic value gains more proportion.

Fashion is well established in the concentric circles of the creative industry. This sector, even though it accumulates greater value as a physical object, generates goods and services that are the result of creativity (HOWKINS, 2001). It so happens, then, that in fashion, the creative decision process ends up considering the economic dimension as a motivation for creativity (THROSBY, 2001).

This situation has implications for the entire production process (creation, production, distribution and consumption), the configuration of companies, the use of technologies, the definition of business and operations models and, not least, the relationship strategies with the consumer.

From this juncture, the arguments that insert fashion in the creative industry and allow for scientific debate become plausible, especially developing themes such as innovation, entrepreneurship and consumption. Subjects listed, in fact, in the scientific articles that make up the dossier, selected with the aim of contributing to reflections both in theoretical aspects and in practices articulated to this axis of fashion: the creative industry.

In this sense, to open the dossier, we present the article "Innovation, conformity and other ambivalences in fashion 
design", which aims to problematize creation and creativity in fashion design practices. Amanda Queiroz Campos starts from a reflection on the fashion system and market, innovation and innovation in the fashion sector, creative process of fashion products, he also analyzes data collected through research on a fashion designer agency, proposing a clipping that emphasizes dialectics such as creation versus adequacy, as well as innovation versus safety. Thus, this work elucidates some of the challenges faced by fashion professionals in the process of managing creativity by reconciling aesthetic and symbolic aspects with economic and competitive aspects, which surround the fashion universe.

The dossier has an important international contribution, the work "Creative Entrepreneurship: the guidelines of the fashion design sector in Lisbon by the perception of creative producers", by Maria Débora Fernandes Pontes, Maria Alice Vasconcelos Rocha and Hans da Nóbrega Waechter. In the article, the author presents the reality of the fashion design sector in the city of Lisbon, identifying the changes in the local market, especially those that took place between 2010 and 2018, and in the face of the economic crisis experienced in the country. To this end, it conducts an investigation with five local Design producers (We Make, Wetheknot, Real Slow Retail Concept Store, Embassy and LxFactory) which make it clear that factors such as tourism, gastronomy, collaborative work and innovation were not only fundamental. for the survival of small entrepreneurs in the face of the economic crisis, but also for the transformation of Lisbon, which has become a reference in innovation and creative entrepreneurship in the last decade.

Subsequently, in the article "Fashion, Consumption and Trends: how television and digital influencers instigate fashion in Brazil", by Teresa Campos Viana Souza and Rita Ribeiro, 
firstly addresses the concepts of fashion and trend, to later present a historical review of the development of the media in the Brazilian context, highlighting the television media as one of the main vehicles adopted by companies in the fashion sector to influence the population's consumption, using nationally recognized celebrities. It also addresses the emergence of the internet, which accelerated the information exchange process, expanded the reach of companies in relation to their audiences and gave rise to digital influencers - a strong strategy for selling products from the most diverse sectors, especially fashion, by the possibility of bringing celebrities closer to the public of a certain brand. The author concludes that the changes in society, which have taken place in recent decades, have changed what is consumed and how it is consumed. More than a product, nowadays attitudes and lifestyles are also consumed.

The work "Ostomy and clothing: a primer on developing clothing for ostomized people", by Mariana Luísa Schaeffer Brilhante, Valdecir Babinski Júnior, Mariana Moreira Carvalho, Icleia Silveira and Lucas da Rosa, stands out in the dossier for its informative character, dealing with an underexplored theme in the fashion and apparel scene, as well as contributing to the awareness of professionals in the fashion sector by thinking of clothing as one of the elements of inclusion. The article initially presents a bibliographical survey on ostomy and retrieves data from a survey carried out with ostomized people, which aimed to identify the main demands and difficulties of this public with regard to their clothing. Based on this set of information, the author presents a guide for the development of clothing for people with an ostomy.

Finally, the article "Covid 19, threatened humanity and the latent desire to consume fashion items: the eternal return of desire?" evokes our attention for the topicality of the theme it 
encompasses and for addressing the issue of individuals' need to consume fashion even in the face of an international health crisis. To reflect on such behavior, Flávia Zimmerle da Nóbrega Costa and Andréa Barbosa Camargo resort to the thinking of philosophers such as Gilles Lipovetsky, Gilles Deleuze and Michel Foucault and analyze the reality witnessed in various world capitals, as the reopening of stores of major fashion brands it generated agglomerations of people eager to consume and, thus, satisfy their individual desires at the expense of thinking collectively.

From this set of articles that make up the dossier, we hope to open and expand the spaces for reflection on these two themes, in such a way that the reading of the works serves as an invitation and a stimulus to readers, researchers and others interested in deepening the debate on fashion in the context of the creative economy. Happy reading everyone!

\section{References}

THROSBY, David. Economics and culture. Cambridge: Cambridge University Press, 2001.

THROSBY, David. The concentric circles model of the cultural industries. Cultural Trends, vol. 17, no. 3, p. 147-164, Sept. /2008.

HOWKINS, John. The Creative Economy - how people make money from ideas. London: Penguin Books, 2001. 